\title{
Conquista da autonomia integral, em mulheres, através de projeto social e instrumento de training sociopsicológico
}

\author{
Josiane Beatriz Piccin Barbieri \\ Maria Tereza Andreola \\ Faculdade Antonio Meneghetti - São João do Polêsine, RS, Brasil
}

\begin{abstract}
Resumo
Este artigo objetiva a apresentação do Projeto Social Mulher do Milênio e dos resultados atingidos ao longo dos mais de dez anos de sua existência, os quais se deram através de eventos de formação dirigidos exclusivamente a mulheres, mirando sua preparação ao ingresso e atuação no novo milênio, com uma consciência que discute e problematiza estereótipos e propõe modos de ser, pensar e agir coerentes com sua identidade. Tudo isso através de um suporte teórico e vivencial que visou torná-las aptas à conquista de uma autonomia integral. Neste sentido, este projeto também está alinhado e contribui para o alcance do $3^{\circ}$ Objetivo de Desenvolvimento do Milênio - Autonomia da Mulher e Igualdade de Gêneros, promulgado pela ONU no ano de 2000. Por meio de uma pesquisa realizada no ano de 2010, constatou-se, junto ao segmento feminino participante do projeto, que os objetivos propostos foram alcançados. Como resultado, avanços no âmbito da autoestima; da realização profissional; do ganho de autonomia moral, psíquica e financeira; da saúde e do bem-estar foram verificados com índices significativos. Salienta-se que o referido projeto embasa-se em teorias de desenvolvimento da personalidade feminina, centrando-se na abordagem ontopsicológica, além de utilizar-se da metodologia de training sociopsicológico, com enfoque no residence de autenticação, os quais, conjuntamente, promoveram a conquista da autonomia integral das mulheres investigadas.
\end{abstract}

Palavras-chave: Mulheres, Autonomia, Projeto social, Training sociopsicológico.

\section{Full autonomy conquering by women through social project and psychological social training instruments}

\begin{abstract}
This article aims to introduce the Millennium Women Social Project and results acquired in the ten years of its existence, which were also obtained through educational events especially focused on women, aiming to their preparation to participate and perform in the new millennium with an awareness that discusses and takes on stereotypes and proposes ways of behaving, ways to thinking and acting in a consistent manner, according to its identity. This was performed with the employment of a theoretical and experienced life support aiming to the conquest of integral autonomy. In this sense, this project is aligned with and contributes to the accomplishment of the $3^{\circ}$ Development Objectives of the Millenium - Women's Autonomy and Gender Equality promoted by the United Nations in 2000. Through a research that took place in 2010, it has been verified that the objectives settled were reached by the part of the feminine segment that participated of the project. As a result, advances in self-esteem area; professional achievements; moral, physical and financial autonomy conquers; and also from the health and wellness domains were verified with significant indexes. It is emphasized that such project is based on women personality development theories centered in the ontopsychology approach, besides using a psychological social training, focusing on the authentication residence that, altogether, promoted the conquest of integral autonomy of the investigated women.
\end{abstract}

Keywords: Women, Autonomy, Social Project, Psychogical social training.

Endereço para correspondência: Josiane Barbieri. Avenida Nove de Julho, 3183, apt 82. São Paulo/SP, Brasil. CEP: 01407-000. E-mail: Josiane@metanoiadirigencial.com.br.

Trabalho apresentado durante a $41^{\mathrm{a}}$ Reunião Anual da Sociedade Brasileira de Psicologia. 


\section{Conquista de autonomía integral en mujeres a través de proyecto social e instrumentos de training sócio-psicológicos}

\section{Resumen}

Este artículo tiene como objetivo presentar el Proyecto Social Mujer del Milenio y los resultados obtenidos a lo largo de más de diez años de existencia, los cuales fueron obtenidos a través de eventos de formación dirigidos exclusivamente a las mujeres, teniendo en vista su preparación al ingreso y actuación del nuevo milenio con una consciencia que discute y problematiza estereotipos y propone modos de ser, pensar y actuar de acuerdo con su identidad. Todo eso a través de un soporte teórico y vivencial que tiene como objetivo hacerlas aptas para la conquista de una autonomía integral. En ese sentido, este proyecto también está alineado y contribuye para el alcance del $3^{\circ}$ Objetivo de Desarrollo del Milenio - Autonomía de la Mujer e Igualdad de Géneros, promulgada por la ONU en el año 2000. Por medio de una encuesta realizada en el año 2010, pudo verificarse, junto al segmento femenino participante del proyecto, que los objetivos propuestos fueran alcanzados. Como resultado, avances en el ámbito de la autoestima; de la realización profesional, de la autonomía moral, psíquica y financiera; de la salud y del bien estar, fueron verificados con índices significativos. Es importante decir que el referido proyecto está basado en teorías de desarrollo de la personalidad femenina, concentrándose en el abordaje ontopsicologico, además de utilizar la metodología de training socio-psicológico, con enfoque en el residence de autenticación, los cuales, conjuntamente, fomentaron la conquista de la autonomía integral de las mujeres investigadas.

Palabras clave: Mujeres, Autonomía, Proyecto Social, Training socio-psicológico.

\section{Introdução}

O tema mulher já foi explorado por inúmeros estudiosos, em áreas do conhecimento como a Psicologia, Antropologia social e a Sociologia. O direito ao voto, ao estudo, à participação ativa na vida econômica e social the foi tardiamente reconhecido e por ela exercido, fatos que deixaram vestígios, tanto na consciência, como no inconsciente individual e coletivo feminino. Ainda hoje, constata-se a participação minoritária da população das mulheres nos âmbitos intelectual, econômico, político e social em relação aos homens. Diante deste panorama, impõem-se as questões: o que mantém a mulher nessa condição? Seriam os condicionamentos históricos, a mentalidade cultural das diversas nações, os conflitos interiores ainda não elaborados adequadamente pela própria mulher ou, então, uma sociedade injusta, a qual não consente a igualdade de gênero e o desfrute dos direitos universais do humano com equidade entre mulheres e homens?

Para além destes questionamentos, e devido à importância da mulher na construção de uma sociedade equilibrada, a Organização Mundial das Nações Unidas, ao estabelecer os
Objetivos para o Desenvolvimento do Milênio ${ }^{1}$, incluiu "promover a igualdade entre os sexos e a autonomia das mulheres" (ONU, 2000, p.9), que corresponde ao terceiro ODM. Além de requerer a igualdade entre os sexos para todos os níveis da sociedade, este objetivo clama pela ação contra o preconceito, pela ampliação das oportunidades de emprego, pela ascensão das mulheres ao mercado de trabalho, por salários iguais ao dos homens para as mesmas funções exercidas, pela ocupação de papéis ativos no mundo econômico e na política, enfim, pelo o desenvolvimento de atividades para a conquista de sua plena autonomia.

\footnotetext{
1 Em 2000, durante os eventos da Cúpula do Milênio, promovido pela Organização das Nações Unidas (ONU), 191 chefes de estado acataram a Declaração do Milênio, um compromisso político que sintetiza várias das importantes conferências mundiais da década de 1990 e pronuncia as prioridades globais de desenvolvimento. A Declaração ressalta que, para alcançar esses objetivos, é necessário promover os direitos humanos de todas as pessoas. Em especial, reconhece a promoção do direito da mulher à igualdade de gênero como sendo criticamente imperativo para a evolução social.
} 
Sob este aspecto, é importante considerar que o campo de atuação profissional possui fundamental importância na conquista da autoestima e independência por parte de qualquer indivíduo, bem como para a construção de uma identidade civil, aquisição de reconhecimento social e acesso aos bens de consumo ou outras dimensões, materiais ou emblemáticas, de grande relevância para a vida em sociedade no século XXI.

O Brasil já se encontra num caminho de diminuição das desigualdades, ainda que não no ritmo desejado. No entanto, não se pode deixar que os avanços ofusquem os desafios ainda existentes. Segundo Pérez Sedeño (2001), as diferenças de gênero e raça no mercado de trabalho são ainda muitas e intensas, e pela sua particularidade estrutural, difíceis de serem rompidas. Qualquer variável que se empregue para esclarecer aspectos desta questão mostra que as desigualdades entre os sexos se apresentam com razoável regularidade estatística.

Geralmente, as desigualdades de gênero se traduzem em duas formas básicas, fortemente assentadas em manifestações de discriminação: desigualdade hierárquica, que se refere às mulheres subrepresentadas nos cargos superiores; e desigualdade territorial, que se refere ao fato das atividades econômicas se apresentarem como se possuíssem sexo, ou seja, as mulheres estão mais presentes em algumas atividades e afastadas de outras, seguindo a cultura de gênero.

O projeto social "Mulher do Milênio", utilizando-se da compreensão e da metodologia ontopsicológica, parte como proposta alternativa e resolutiva ao problema do protagonismo e da realização existencial da mulher. Desde seu início, se propõe à compreensão da mulher enquanto "inteligência ao feminino", pois parte do princípio de que a inteligência não possui sexo. Desta forma, procura a profunda responsabilização da mulher para que ela assuma, em primeira pessoa, a própria história, dando seu contributo de eficiência a uma sociedade que carece de suas habilidades plenamente desenvolvidas e exercitadas.

Parte da premissa, igualmente, de que as mulheres "empoderadas" (do inglês, empowerment) dão um contributo maior para as suas famílias e para a sociedade em geral, ao receberem remunerações mais elevadas, ao promoverem uma educação qualificada aos seus filhos e ao saberem mais sobre cuidados de saúde. Politicamente, são elas que possuem maior probabilidade de conhecer e defender os seus direitos e promover o desenvolvimento local, que posteriormente repercute no contexto global.

\section{1 - O Projeto Mulher do Milênio}

O Projeto Mulher do Milênio constitui-se em um processo contínuo e permanente de formação, qualificação e empoderamento das mulheres, tendo como escopo uma nova inteligência ao feminino, responsabilizando a mulher pela conquista de sua autonomia e consequente liderança pessoal, profissional e social.

Este projeto é uma iniciativa da Associação Brasileira de Ontopsicologia (ABO), em conjunto com a Associação Internacional de Ontopsicologia (AIO) e o Centro Internacional de Arte e Cultura Humanista Recanto Maestro, além de várias instituições parceiras. Ele foi iniciado ainda nos anos de 1990, quando a ABO e a AIO já tinham a consciência e a intenção do resgate da inteligência ao feminino como condição fundamental para a evolução do humano e da sociedade como um todo. Após conferências e eventos em diversas nações, marca-se o início do novo milênio com o Congresso Internacional "A mulher do terceiro milênio: as prerrogativas da inteligência feminina como raiz ao novo milênio", realizado no Rio de Janeiro, no período de 28/12/1999 a 01/01/2000.

Em termos de abrangência, foram realizados 60 eventos no período de 1990 a 2010, que contaram com a participação de 6.930 mulheres. Dentre os temas abordados, estão: saúde, estereótipos coligados ao gênero, autonomia, liderança e desenvolvimento econômico de mulheres.

As diversas atividades, como congressos, cursos, palestras, residences, cinelogias, baseados na teoria e instrumentos de intervenção formalizados pela escola ontopsicológica, contribuíram no preparo das mulheres para o ingresso no novo milênio com base numa consciência livre de estereótipos e preconceitos, dando-lhes condições para assumir iniciativas empreendedoras e cargos de liderança com responsabilidade, racionalidade e 
competência, com atitude de reciprocidade e integração entre os planos pessoal e social.

A formação por meio da metodologia ontopsicológica porta uma visão original e alternativa, baseada em três pontos principais: 1) uma nova abordagem da Psicologia feminina, fundamentada no princípio ônticohumanista ${ }^{2}$ 2) o papel da mulher na atualidade sociológica da estrutura da globalização; e 3) responsabilização da mulher perante a sua suposta condição de inferioridade em relação ao gênero masculino (Meneghetti, 2000).

A discussão do tema autonomia da mulher $e$ igualdade de gêneros consente distintas abordagens. A contribuição que se aportou, com este projeto, relaciona-se, especialmente, com a importância da superação do modelo tradicional de significação do papel da mulher na esfera produtiva, a fim de promover sua maior participação no cenário público, a qual pode ser expressa numa maior e mais qualificada inserção no mercado de trabalho, na ascensão profissional e na sua ampla presença em cargos de poder e decisão.

Esta abordagem está em consonância com o Plano Nacional de Políticas para as Mulheres $^{3}$, especialmente nas seguintes áreas temáticas: a) autonomia econômica e igualdade no mundo do trabalho, com inclusão social; b) educação inclusiva, não sexista, não racista, não homofóbica e não lesbofóbica; c) participação das mulheres nos espaços de poder; d) cultura, comunicação e mídias igualitárias, democráticas e não discriminatórias; e) enfrentamento das desigualdades geracionais que atingem as

2 O princípio ôntico-humanista, na escola ontopsicológica, é denominado Em Si ôntico. O Em $\mathrm{Si}$ ôntico é o ponto dinâmico, semovente e inteligente que constitui a individuação humana. É constitutivo e constituinte base da individuação existencial, o qual transcende os modelos operativos de consciência pelo fato de ser o agente causante da multiplicidade dos efeitos que produz, sendo que nenhum destes efeitos, singularmente, pode conter a sua totalidade. É possível de ser colhido somente através da evidência de seu portador, mas pode ser verificado na sua fenomenologia, nos resultados eficientes, otimais e de crescimento da individuação humana.

${ }^{3}$ No ano de 2008, foi lançado o II Plano Nacional de Políticas para as Mulheres pela Secretaria Especial de Políticas para as Mulheres. (Presidência da República, 2008). mulheres, com especial atenção às jovens e idosas.

O modelo de formação propõe um novo paradigma, prioritariamente através do questionamento dos referenciais subjetivos de gênero e do fortalecimento da identidade e inteligência femininas, podendo contribuir para a alteração do quadro atualmente existente nas diversas nações e possibilitar uma participação ativa e sustentável da mulher na sociedade brasileira e na comunidade internacional.

\section{2 - O Projeto Mulher do Milênio e a aplicação do training sóciopsicológico}

O Projeto Mulher do Milênio possui uma metodologia de trabalho formativa que implica elementos teóricos e atividades práticovivenciais, realizadas por meio de diversos eventos: congressos, residence, cursos e palestras, além da publicação de artigos e livros que permitem um estudo mais aprofundado das temáticas abordadas.

De todas estas atividades, a que se mostrou mais fecunda, no sentido dos resultados que as mulheres podem obter, é a modalidade de training sociopiscológico, denominado residence (Meneghetti, 2005a), que consiste num estágio residencial full immersion, de três a sete dias, para grupos selecionados, durante o qual é realizada a verificação do modelo de vida e a revisão crítica das condutas mentais dos participantes, a fim de variá-las ao escopo de uma gestão eficiente de si mesmos e de suas relações sociais, sempre em conformidade com a identidade de natureza individual ${ }^{4}$.

$\mathrm{O}$ local em que acontece o residence deve ser um ambiente ecologicamente sadio e simples, construído dentro de uma cultura humanística, que permita às participantes um contato amistoso e revigorante com a natureza. Todos os espaços de palestras, trabalhos de grupo, refeições e outros tipos de atividades, especialmente aqueles para dormir e para estudo, devem ser harmoniosos e bem proporcionados. Os quartos devem ser preferencialmente individuais. $\mathrm{O}$ ambiente humano de um residence também necessita ser

\footnotetext{
4 Identidade, de acordo com a abordagem ontopsicológica, "é a forma que especifica em si o objeto ou indivíduo e o distingue de qualquer outro" (Meneghetti, 2008, p. 134).
} 
agradável, permitindo um convívio prazeroso entre as participantes, as quais têm entre si o mesmo objetivo de imersão e introspecção com sério compromisso pessoal.

É importante que seja respeitado o absoluto aspecto privado de livre escolha e disponibilidade de cada participante em cada momento do residence. Um técnico capacitado para tal conduz as atividades durante este estágio residencial de modo a tornar evidentes as potencialidades fundamentais ou o $\mathrm{Em} \mathrm{Si}$ ôntico de cada uma das participantes.

O caráter de imersão, isto é, o distanciamento do indivíduo do seu ambiente social, ausenta o sujeito do seu costumeiro modo de vida, onde já estão estruturadas todas as suas relações, estereótipos e modelos de comportamentos. Desta forma, ele pode avaliar de modo prático aquilo que em sua vida cotidiana é côngruo ou distônico ao seu bem estar e desenvolvimento criativo.

Durante o residence, e também nos demais eventos, as mulheres têm a oportunidade de, através da abordagem ontopsicológica sobre a feminilidade ${ }^{5}$, rever seus valores e sua impostação perante si mesmas e a sociedade (compreendida no conjunto de suas manifestações: família, casamento, escola, mundo do trabalho, cultura etc.), responsabilizando-se e adotando condutas funcionais para a aquisição de sua autonomia, o desenvolvimento de suas aptidões e de sua liderança.

Autonomia significa a faculdade de se governar por si mesmo; o direito ou faculdade de se reger (uma nação) por leis próprias; liberdade ou independência moral ou intelectual. $\mathrm{O}$ adjetivo autônomo refere-se a agir sem controle externo (Ferreira, 1986). Conforme Guimarães e Boruchovitch (2004, p. 145), para a Teoria da Autodeterminação, "o conceito de autonomia é vinculado ao desejo ou a vontade do organismo de organizar a experiência e o próprio comportamento e para integrá-los ao sentido do self".

A autonomia é um requisito básico que o sujeito deve alcançar a fim de adquirir sua maturidade e realizar a passagem para o mundo

\footnotetext{
${ }^{5}$ Os principais temas abordados, durante a formação das mulheres do Projeto Social Mulher do Milênio, podem ser consultados na obra de Antonio Meneghetti, La femminilità come sesso, potere, grazia (2007).
}

adulto com uma identidade pessoal, civil e profissional bem delineada, a ponto de receber, ao mesmo tempo, o reconhecimento dos que o cercam. A partir da obtenção da maturidade psicológica, moral e da conquista de sua autonomia, a mulher pode, então, considerar-se uma cidadã capaz e uma contribuinte de valor no plano familiar, sanitário, econômico, intelectual, social etc.

Outra aprendizagem fundamental para as mulheres nestes eventos de formação é a possibilidade de reconstrução de sua personalidade fundamentada na sua identidade original, através da metodologia ontopsicológica. Esta consente à mulher, além da autenticação de sua consciência (revisão crítica do modo de pensar e agir para colocá-lo em harmonia com o próprio Em Si ôntico), o resgate de sua autoestima e uma realização histórica bem-sucedida, em consonância com seus dotes naturais.

A autorrealização da mulher permite uma evolução serena e autossustentável, ou seja, que se amplifica em resultados sociais, no respeito pela cultura local e pelo meio ambiente. Todo esse aprendizado é incrementado através de atividades práticas, tais como: cinelogia ${ }^{6}$; dinâmicas de grupo temáticas; atividades físicas inseridas em contextos ecobiológicos de alta vitalidade; oficinas de cozinha viva; exercícios práticos para aprendizado de atitudes civis, profissionais e estéticas; entre outras.

Nos eventos, também são tratadas questões específicas que dizem respeito à saúde da mulher, sua opção madura e responsável pela maternidade, ao aprendizado do estabelecimento de relações sexuais criteriosas, evitando assim a transmissão de doenças sexualmente transmissíveis, bem como a problemas de gestação e saúde na primeira infância da criança.

\footnotetext{
${ }^{6}$ A cinelogia é um dos instrumentos de intervenção da escola ontopsicológica, que consiste na instrumentalização do cinema, enquanto ato exposto do inconsciente, com a finalidade de conscientização dos processos psicobiológicos vividos sem o controle consciente do eu. Pode-se defini-la, também, como a análise das dinâmicas emotivas ativadas no espectador pela impressão ou pelo contato com as imagens que escorrem durante a projeção fílmica.
} 


\section{3 - A efetividade do Projeto Mulher do Milênio: metodologia de avaliação}

Para medir a efetividade dos resultados alcançados pelo presente projeto, em 2010, estabeleceram-se os seguintes procedimentos:

1 - Realização de uma pesquisa exploratória com as participantes do projeto;

2 - Levantamento da posição ocupada pelas mulheres, em cargos de liderança, nas empresas localizadas no distrito Recanto Maestro/RS (consultar www.recantomaestro.com.br).

A pesquisa exploratória foi realizada com 60 mulheres, todas participantes do projeto, brasileiras e residentes no Brasil, com idades entre 23 e 60 anos, de diferentes profissões, com o intuito de mensurar os resultados obtidos depois das atividades prático-vivenciais cumpridas no período de 10 anos.

A hipótese levantada foi de que as mulheres do Projeto Mulher do Milênio obtêm aumento de resultados nas esferas da produção científica; saúde e bem-estar; ganho econômico; autonomia psicológica; autonomia moral; grau de instrução; empreendedorismo; superação dos estereótipos relativos ao gênero e participação em projetos sociais - esferas definidas como indicadores da autonomia integral pelas pesquisadoras.

\section{1 - Metodologia da pesquisa}

Segundo Gil (1988), a pesquisa exploratória tem como objetivo proporcionar maior familiaridade com o problema com vistas a torná-lo mais explícito. Classificou-se, então, o presente estudo como exploratório, na medida em que seu foco foi obter maior familiaridade com o público alvo. Contemporaneamente, tratou-se de uma investigação qualiquantitativa, por coletar e analisar dados numéricos, mas que igualmente examinou e refletiu a respeito das percepções dos sujeitos pesquisados para obter o entendimento de suas ações sociais e humanas.

A coleta dos dados deu-se através de um questionário semiestruturado, preliminarmente submetido a exame piloto com dez mulheres, todas elas participantes do projeto, escolhidas aleatoriamente. Verificada sua eficácia, no sentido de gerar os dados pretendidos, passouse para sua aplicação em maior escala.
O questionário foi composto por 25 perguntas, sendo sete optativas e 18 dissertativas. As questões de número um a 15 versaram sobre as características pessoais do sujeito indagado, como a sua formação, naturalidade, profissão e amplitude de atuação profissional. As interrogativas 16 e 17 fizeram referência ao engajamento com os Objetivos de Desenvolvimento do Milênio ou atuação em Organizações Não Governamentais. $\mathrm{Na} 18^{\mathrm{a}}$, as participantes foram convidadas a classificar tópicos como pertencentes ao gênero masculino, feminino ou a ambos, conforme a sua concepção. Nos ítens 19 a 22, a temática abordada envolveu a relação da investigada com o Projeto Mulher do Milênio: de quantos encontros participou? Desde quando o conhece? Participou do Congresso Donna 2000 (Congresso Internacional realizado entre e 28 de dezembro de 1999 a $1^{\circ}$ de janeiro do ano 2000, organizado pela AIO - Associação Internacional de Ontopsicologia e ABO Associação Brasileira de Ontopsicologia. Esta última é a idealizadora do Projeto Mulher do Milênio)? Por fim, as questões 23 a 25 indagaram sobre a mudança provocada na vida das mulheres pelo Projeto Mulher do Milênio, estabelecendo uma comparação entre antes e depois de sua participação nas atividades formativas, em relação aos seguintes quesitos: saúde, evolução na vida pessoal, ganho econômico, autonomia psicológica, autonomia moral, ganho de empreendedorismo e produção intelectual.

O questionário foi aplicado de modo impresso àquelas que se propuseram a respondê-lo de modo espontâneo, assinando um termo de consentimento para a utilização das respostas exclusivamente para os fins da pesquisa em questão. Na coletânea dos dados, todas as respostas foram compiladas para planilhas digitais do Microsoft Office Excel, que foi programado para não abranger casas decimais nos cálculos de porcentagem. Depois de digitadas, as informações foram transformadas em tabelas, para que destas fossem extraídos os gráficos, o que facilitou a sua leitura e posterior análise. Neste ponto, houve duas maneiras de classificação dos resultados: a) em questões fechadas ou optativas - cuja resposta consistia em assinalar uma dentre outras alternativas - sendo que as categorias utilizadas nos gráficos foram as respostas que já haviam sido pré-definidas pelos pesquisadores no momento da elaboração 
do questionário; b) em questões abertas ou dissertativas, cujos gráficos foram estruturados em base a respostas categorizadas pelo exame e classificação de seu conteúdo.

No presente artigo, optou-se por apresentar os resultados referentes às questões de número 16 , 18, e 23, todas optativas. Foram também utilizados os dados obtidos com os questionamentos de caracterização da amostra, como idade, formação e profissão. As informações pertinentes à quantidade de mulheres que ocupam cargos de chefia, bem como a quantidade de mulheres atuantes nas empresas em relação aos homens, foram obtidas através de um levantamento, conforme exposto a seguir.

\section{2 - Levantamento da posição ocupada pelas mulheres, em cargos de liderança, nas empresas localizadas no Distrito Recanto Maestro/RS}

Ainda em 2010, realizou-se o levantamento das empresas ambientadas no Centro Empresarial do Centro Internacional de Arte e Cultura Humanista Recanto Maestro, objetivando verificar a posição de poder e de liderança alcançados pelas mulheres formadas pelo Projeto Mulher do Milênio no ambiente de trabalho. Neste levantamento, realizado junto à administração do local e na prefeitura da cidade onde está localizado o centro, foram relacionadas 14 empresas e entidades, com atuação nacional e/ou internacional. Dentre estes empreendimentos, estão associações, fundação, faculdade, hotel, pousada, editora, empresas de consultoria, software, fábrica de tapetes, lavanderia, negócios nos segmentos de moda, alimentação e cosméticos (http://www.recantomaestro.com.br/pt/centro_e mpresarial.php). Para complementar este levantamento, investigou-se o número de mulheres em relação aos homens, que compunham o quadro de colaboradores dos aludidos negócios e o cargo por elas ocupado nas empresas.

\section{4 - Resultados}

Para averiguar a contribuição do Projeto Mulher do Milênio à formação da inteligência feminina à liderança, nas figuras que seguem, é possível ter uma visão geral dos aspectos investigados e sua evolução no transcorrer do período de 10 anos.

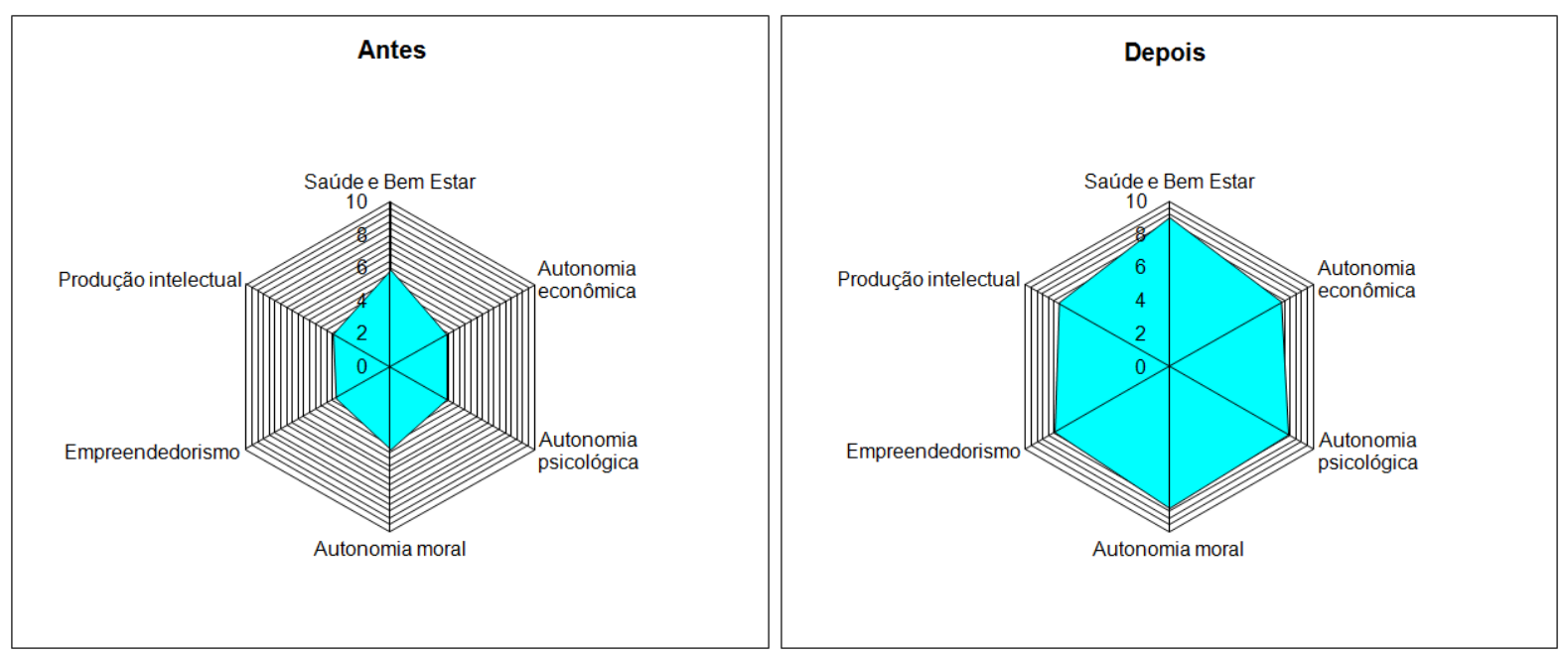

Figuras 1 e 2 - Representação dos resultados antes e depois da participação no Projeto Mulher do Milênio.

\subsection{1 - Saúde e Bem-estar}

No quesito saúde e bem-estar, o índice apontado era de $57 \%$ e, após a participação no projeto, foi atingida uma melhoria na saúde das mulheres de $100 \%$.

Os índices alcançados evidenciam que a participação das mulheres em atividades formativas do Projeto Mulher do Milênio possibilita-lhes melhorias no aspecto de saúde e bem-estar. Este quesito, hierarquicamente, é considerado a primeira expressão do humano funcional em ação e autonomia liderística, segundo os critérios utilizados pela metodologia ontopsicológica: identidade, 
utilitarismo e funcionalidade (Meneghetti, 2010), ou seja, a mulher escolhe, baseando-se na sua identidade, aquilo que é útil para a funcionalidade de sua individualidade histórica.

Para a Organização Mundial da Saúde (OMS), o conceito de saúde é um estado de completo bem estar físico, mental e social e não apenas a ausência de doença (WHO, 1946).
Para Meneghetti (2010), "sadio é aquele que registra e modula a sua vida com resultado funcional. $E$ sadio quem funciona $\mathrm{em}$ autoidentidade, isto é, mantém e aumenta a própria identidade funcional" (p. 21). Nesse sentido, a saúde está coligada a um estilo de vida em que, íntegro este pressuposto, é consentida a evolução contínua e criativa.
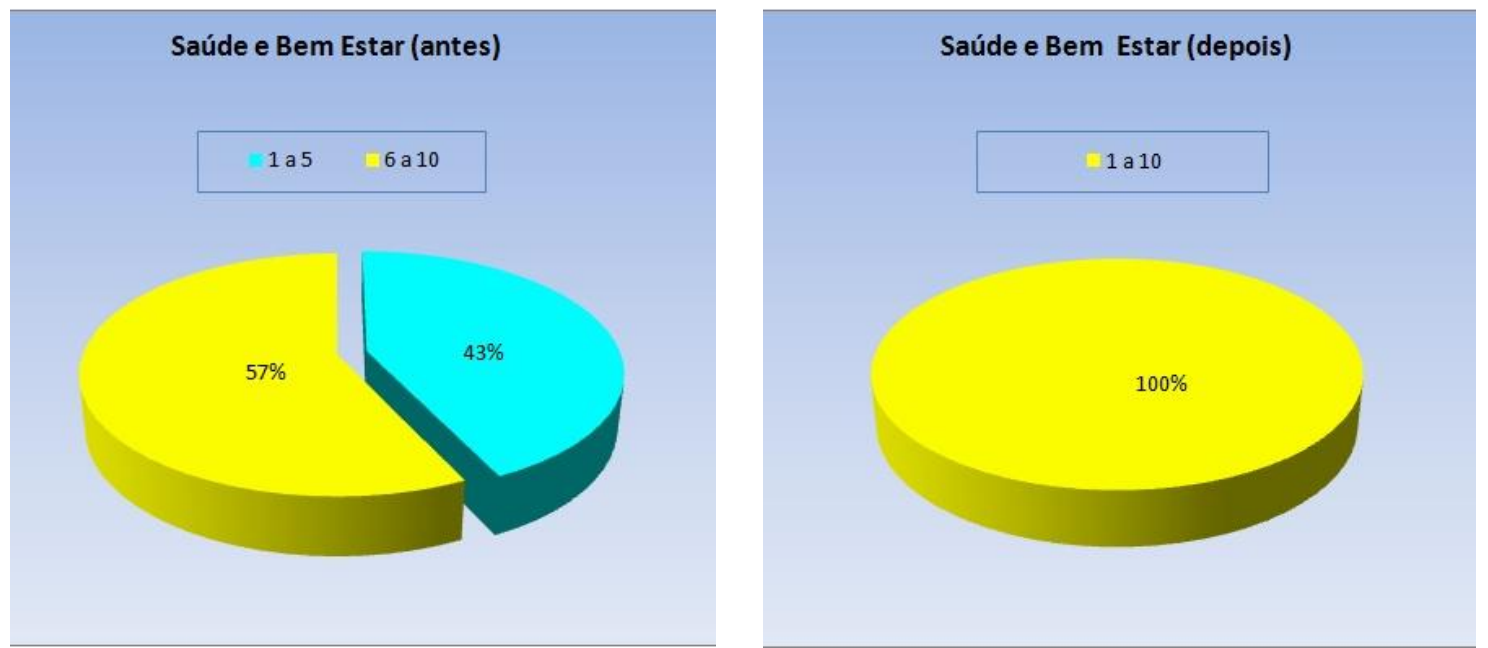

Figuras 3 e 4 - Representação dos resultados referentes à Saúde e Bem-estar antes e depois da participação no Projeto Mulher do Milênio.

\subsection{2 - Autonomia econômica, psicológica e moral}

No quesito autonomia econômica, houve um significativo acréscimo de $29 \%$ para $97 \%$, na pontuação de 6 a 10, conforme pode ser constatado nas figuras abaixo.

Para o Projeto Mulher do Milênio, o primeiro ponto de maturidade existencial da mulher é a base econômica, pois lhe consente a

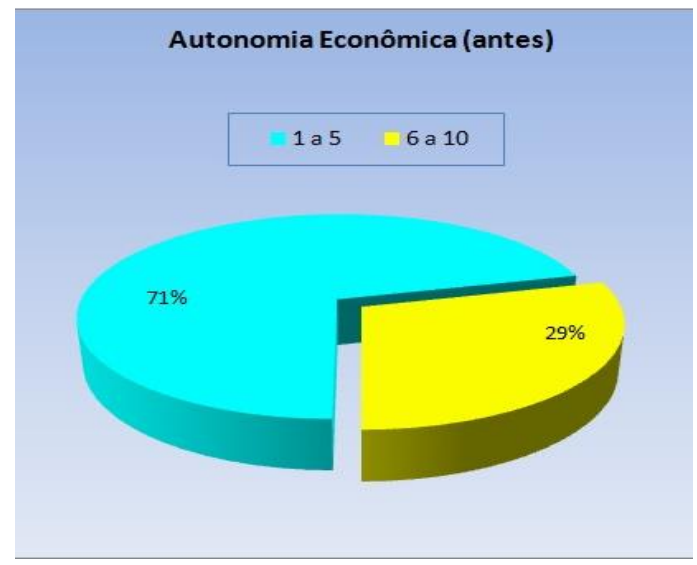

liberdade, a autonomia e o direito de ser. Esta autonomia somente é conquistada através de sua inserção profissional no mercado de trabalho, da ampliação de seu poder de decisão e, sobretudo, pelo exercício de sua cidadania. Conforme a abordagem ontopsicológica, "a educação ao ponto econômico é o princípio da liberdade da pessoa humana" (Meneghetti, 2007, p. 270).

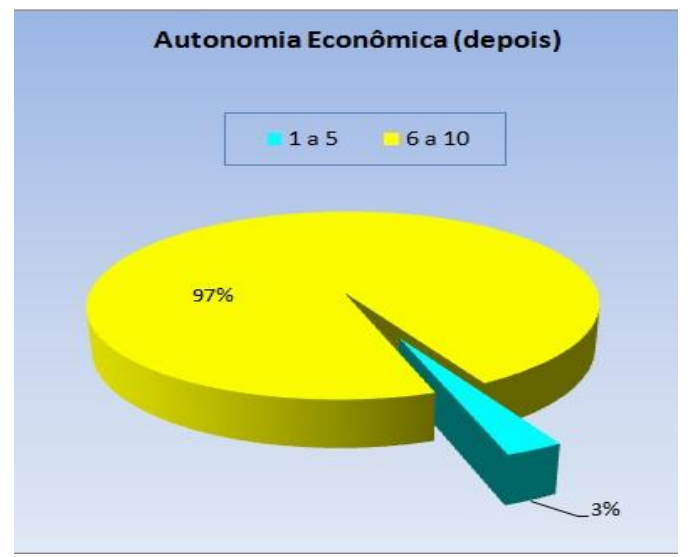

Figuras 5 e 6 - Representação dos resultados referentes à Autonomia Econômica antes e depois da participação no Projeto Mulher do Milênio. 
No que tange à autonomia psicológica, somente $9 \%$ das mulheres pesquisadas consideraram possuí-la antes da participação no projeto, ao passo que, após o seu ingresso no mesmo, $100 \%$ referiram tê-la alcançado, conforme pode ser observado nas figuras 7 e 8 .

A autonomia psicológica diz respeito a uma maturidade psíquica que se manifesta numa capacidade de fazer uma pedagogia de si mesmo como pessoa líder no mundo, com competências e condutas vencedoras (Meneghetti, 2010). Atingida esta maturidade, a mulher pode atuar como agente de transformação social e disseminadora de valores humanistas em todas as esferas relativas à pessoa: afetiva, social, cultural, profissional, política, etc. A autonomia psicológica, por sua vez, incide também na autonomia moral, na promoção da civilidade, do bem comum, perpassando, como efeito multiplicador, por todos os oito Objetivos de Desenvolvimento do Milênio.

A autonomia moral é representada pelas figuras 9 e 10 .

Adquirida uma consciência que relativiza a cultura e os estereótipos relativos ao gênero e atuando em conformidade com sua inteligência natural - que em nenhum caso é passível de prejuízos - revela-se que a mulher adquire total autonomia moral como, de fato, os resultados acima demonstram: antes da participação no Projeto Mulher do Milênio, 40\% das mulheres consideravam possuir autonomia moral, passando este percentual, depois do engajamento no Projeto, para $100 \%$.
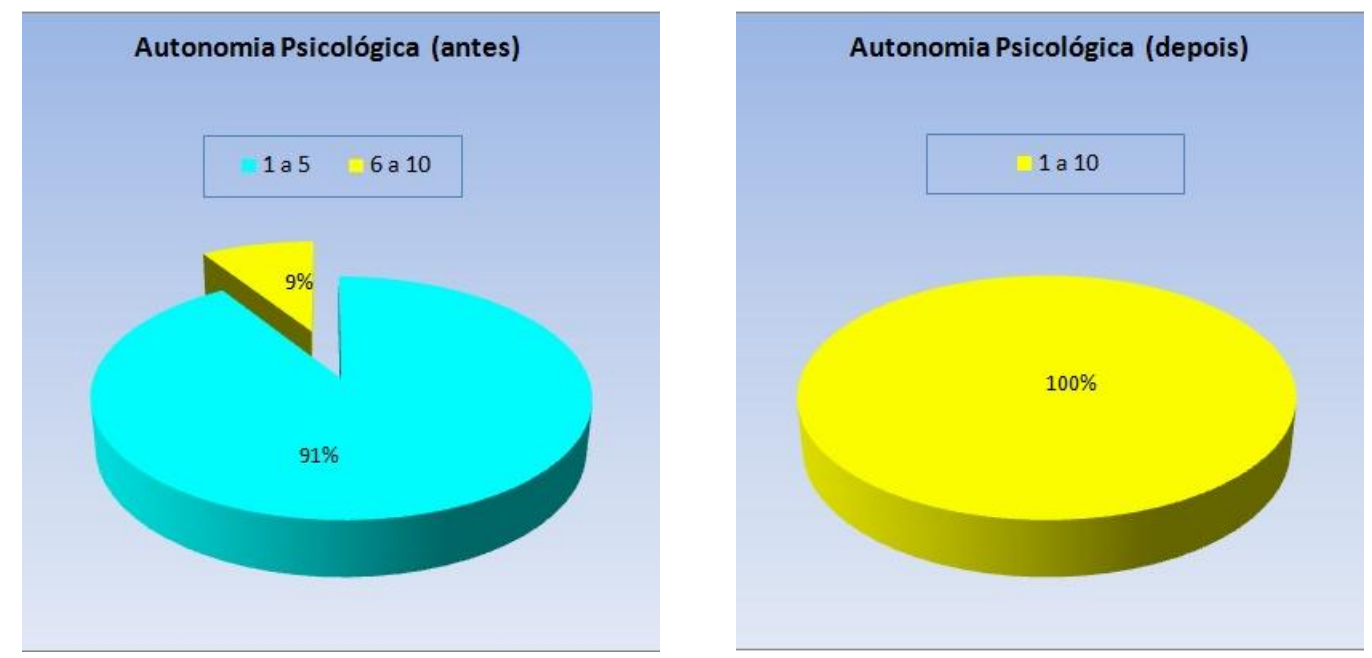

Figuras 7 e 8 - Representação dos resultados referentes à Autonomia Psicológica antes e depois da participação no Projeto Mulher do Milênio.
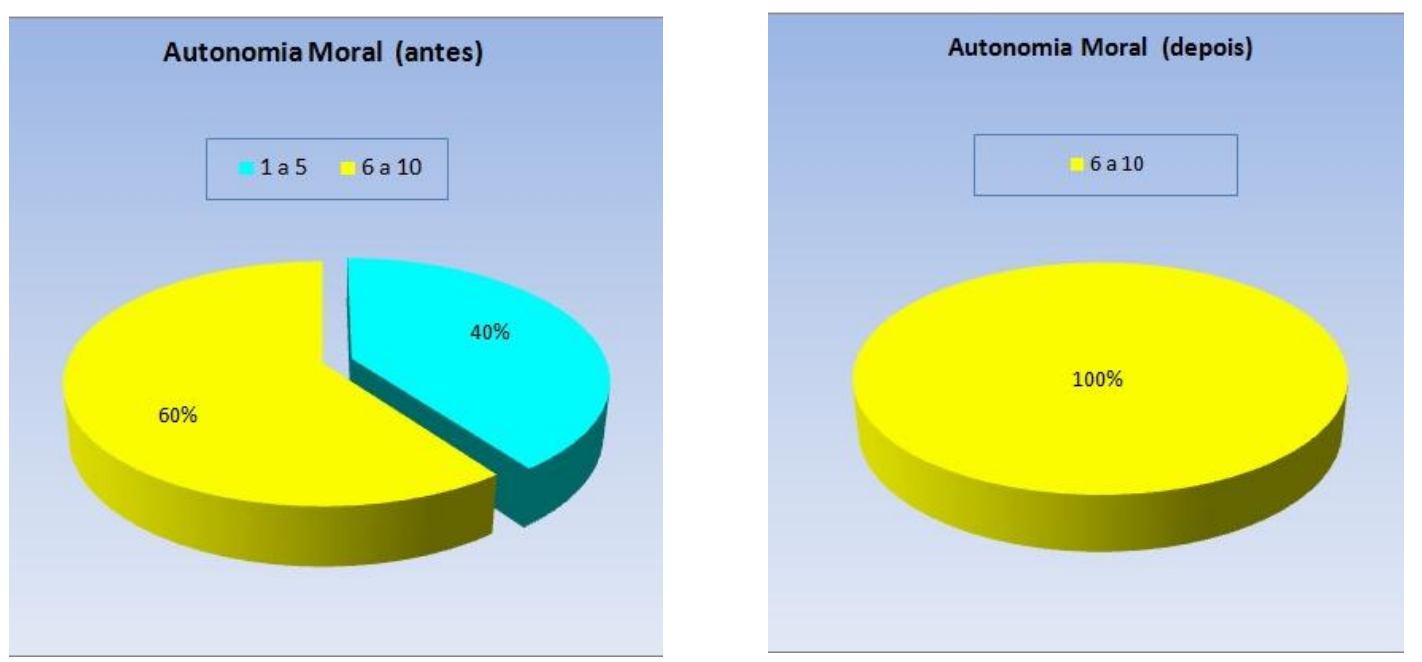

Figuras 9 e 10 - Representação dos resultados referentes à Autonomia Moral antes e depois da participação no Projeto Mulher do Milênio. 


\subsection{3 - Empreendedorismo}

Quanto ao quesito empreendedorismo, somente $14 \%$ das mulheres se consideravam empreendedoras antes de sua participação no Projeto Mulher do Milênio, passando a 97\% após seu ingresso no Projeto, o que representa também a conquista de sua autonomia econômica, ascensão a posições de poder e decisão, geração de novos empregos, aumento da contribuição fiscal e consequente

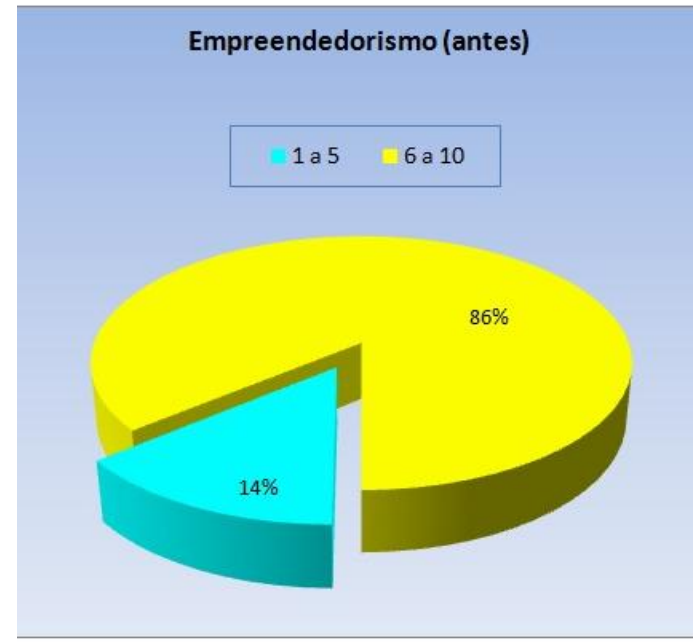

desenvolvimento local.

$\mathrm{Na}$ medida em que as mulheres tornam-se empreendedoras, o Projeto Mulher do Milênio pode considerar-se um contribuinte direto com a iniciativa do Governo Federal quanto ao programa Trabalho e Empreendedorismo das Mulheres, que mira estimular o empreendedorismo feminino, com apoio às mulheres na criação e no desenvolvimento de seus próprios negócios.

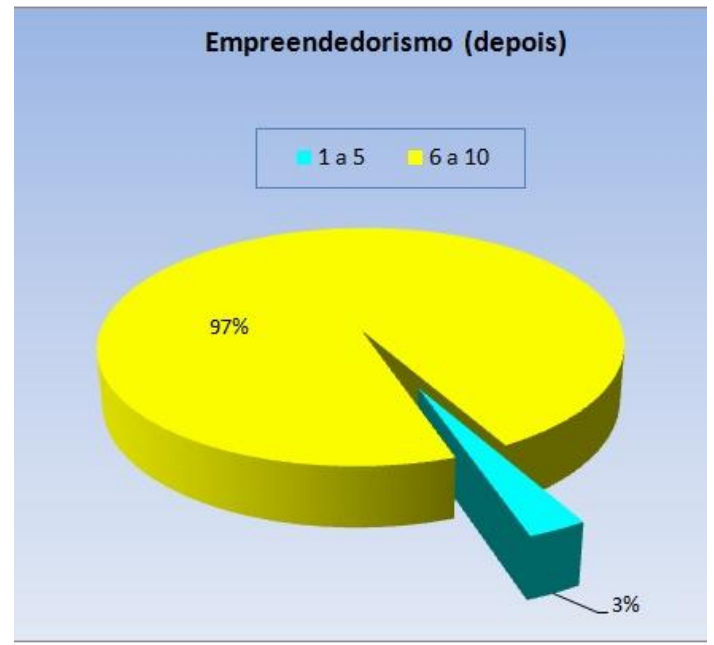

Figuras 11 e 12 - Representação dos resultados referentes ao Empreendedorismo antes e depois da participação no Projeto Mulher do Milênio.

\subsection{4 - Produção Intelectual}

Relativos à produção intelectual, os dados confirmam índices já apontados anteriormente, sendo que, de $23 \%$ de mulheres que referiram produzir intelectualmente antes da participação no Projeto Mulher do Milênio, passou-se para 91\% após o acesso ao Projeto.

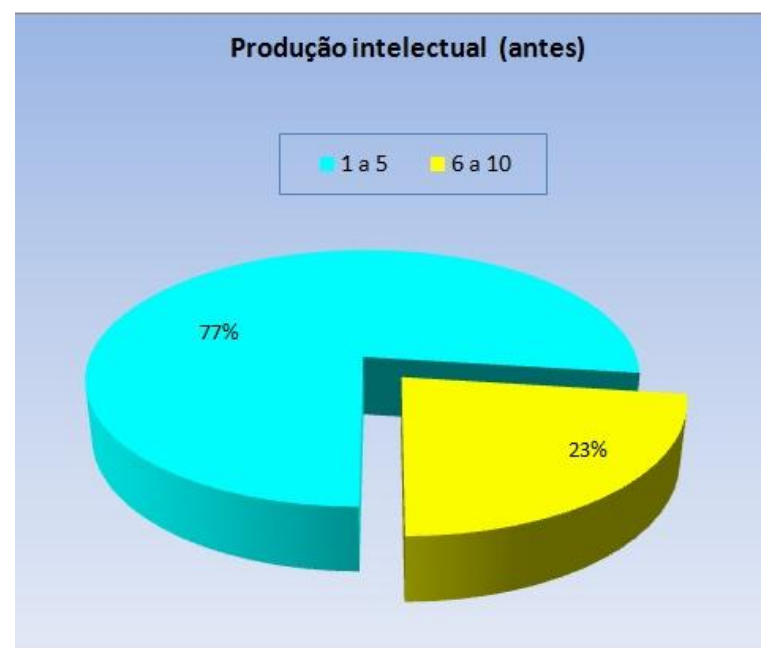

Percebeu-se que a produção intelectual esteve diretamente associada ao nível de escolaridade que foi atingido pelas mulheres que integraram o Projeto Mulher do Milênio, pois no levantamento de dados da pesquisa realizada, o grau de instrução ficou constituído conforme indica a figura 15.

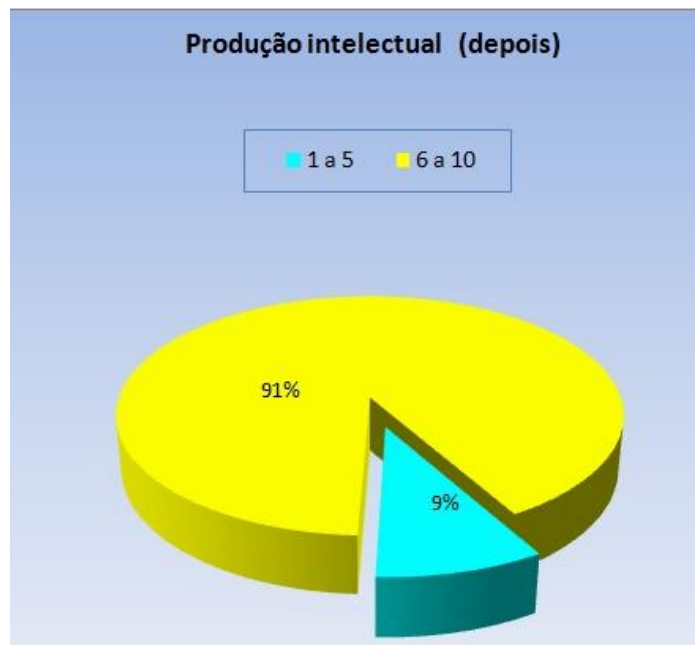

Figuras 13 e 14 - Representação dos resultados referentes à Produção Intelectual antes e depois da participação no Projeto Mulher do Milênio. 


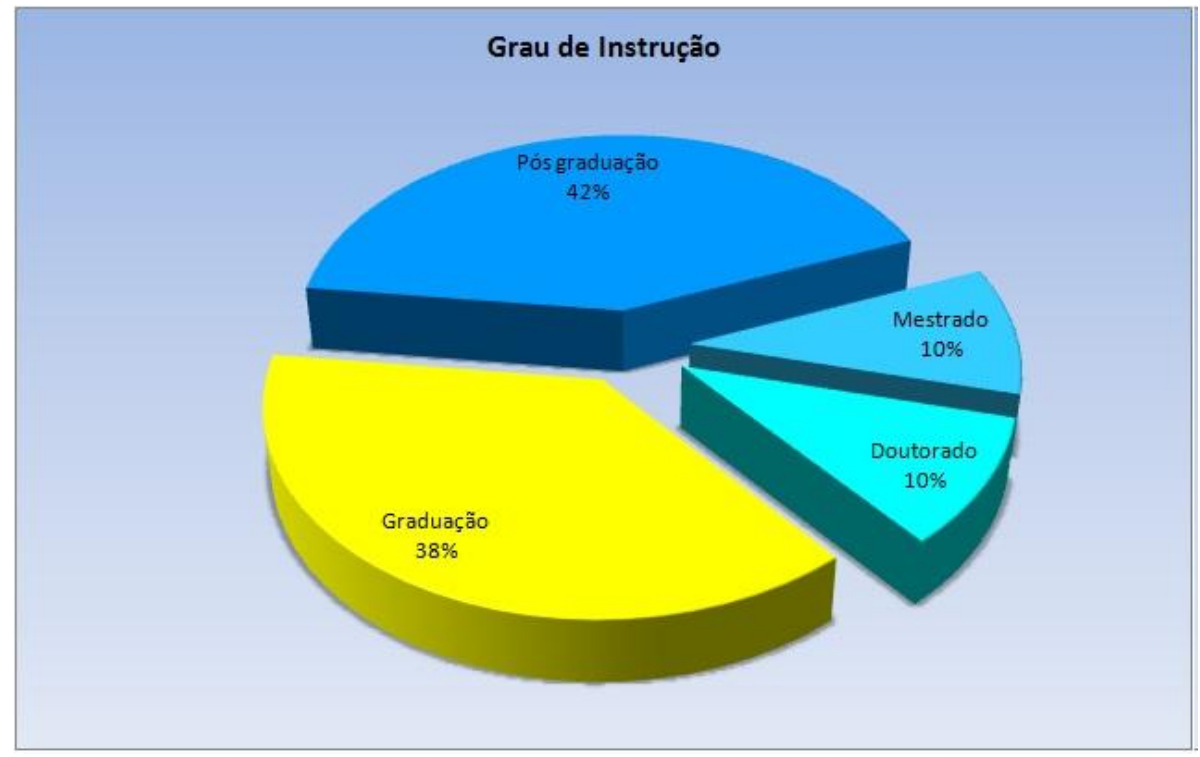

Figura 15 - Representação dos resultados referentes ao Grau de Instrução depois da participação no Projeto Mulher do Milênio.

Segundo a figura 15 , todas as mulheres possuem nível superior, sendo $38 \%$ graduadas e $62 \%$ pós-graduadas, demonstrando que o Projeto Mulher do Milênio pode contribuir de forma expressiva para que as mulheres alcancem níveis mais elevados de formação inclusive chegando ao mestrado e doutorado o que repercute no aumento de salários, de cultura científica e nos demais indicadores relativos ao ODM 3.
Outro ponto expressivo do projeto faz referência à idade das mulheres participantes, conforme se observa na figura 16.

De fato, o Projeto Mulher do Milênio atende a mulheres com diferentes faixas etárias, alcançando desde aquelas consideradas mais jovens, até 24 anos, como aquelas adultas, além de adentrar igualmente na faixa dos 50 anos em diante.

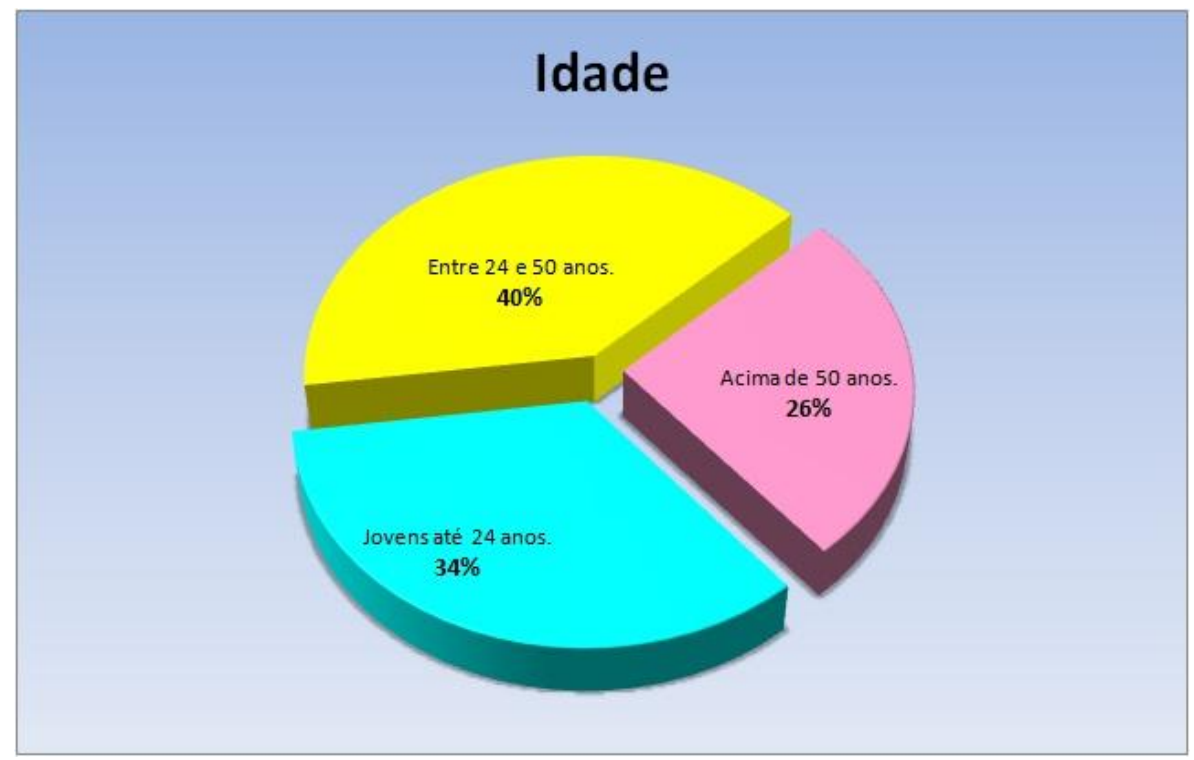

Figura 16 - Representação dos resultados referentes à faixa etária das participantes do Projeto Mulher do Milênio. 
Uma das áreas temáticas, trabalhadas no Plano Nacional de Políticas para as Mulheres, trata justamente do enfrentamento das desigualdades geracionais que atingem as mulheres, com especial atenção às jovens e idosas. Neste sentido, o Projeto Mulher do Milênio coopera para o aprimoramento individual, tendo como foco principal o potencial de ação da mulher independentemente de sua idade, o que rompe com o paradigma das faixas etárias, incidindo de forma harmoniosa em todas as gerações, que passam a cooperar entre si. De fato, sob a ótica ontopsicológica, para além de seu sexo e idade, o humano é um constante vir a ser, é um projeto aberto com potencial de evolução criativa contínua. Por isso, mesmo as mulheres ditas idosas podem ser a expressão concreta, e até mais valorosa, da conquista da igualdade entre sexos e da autonomia por parte das mulheres.

Ressalta-se que o Projeto Mulher do Milênio promove uma formação que transcende a idade das mulheres, requisito fundamental para uma contribuição focada, de forma contrabalançada, tanto em resultados qualitativos, como em quantitativos. Este projeto, norteado por princípios humanitários e de tolerância, tem como premissa que, sobretudo resultados qualitativos podem garantir a sustentabilidade no processo de edificação de uma sociedade economicamente viável e equânime, pois estes determinam o ganho, por parte dos beneficiados pelas ações e políticas sociais, que passa a ser efetivamente incorporado, a longo termo, no exercício cotidiano de suas atividades.

Como se pôde constatar, os índices alcançados demonstram que $\mathrm{o}$ acesso das mulheres a atividades formativas do Projeto Mulher do Milênio possibilita-lhes melhoria nos aspectos supramencionados. Tal conquista acontece paralelamente à aquisição de níveis de formação superior, maior possibilidade de promoção a cargos de liderança e poder.

\subsection{5 - Superação dos Estereótipos}

Neste sentido, outro indicador avaliado na pesquisa refere-se à superação dos estereótipos relativos aos gêneros masculino e feminino. Dentre os modelos de comportamento, elegeram-se, para consulta: autossustento, beleza, empreendedorismo, determinação, formação superior, produção intelectual, raciocínio lógico, senso de justiça e senso de estética.

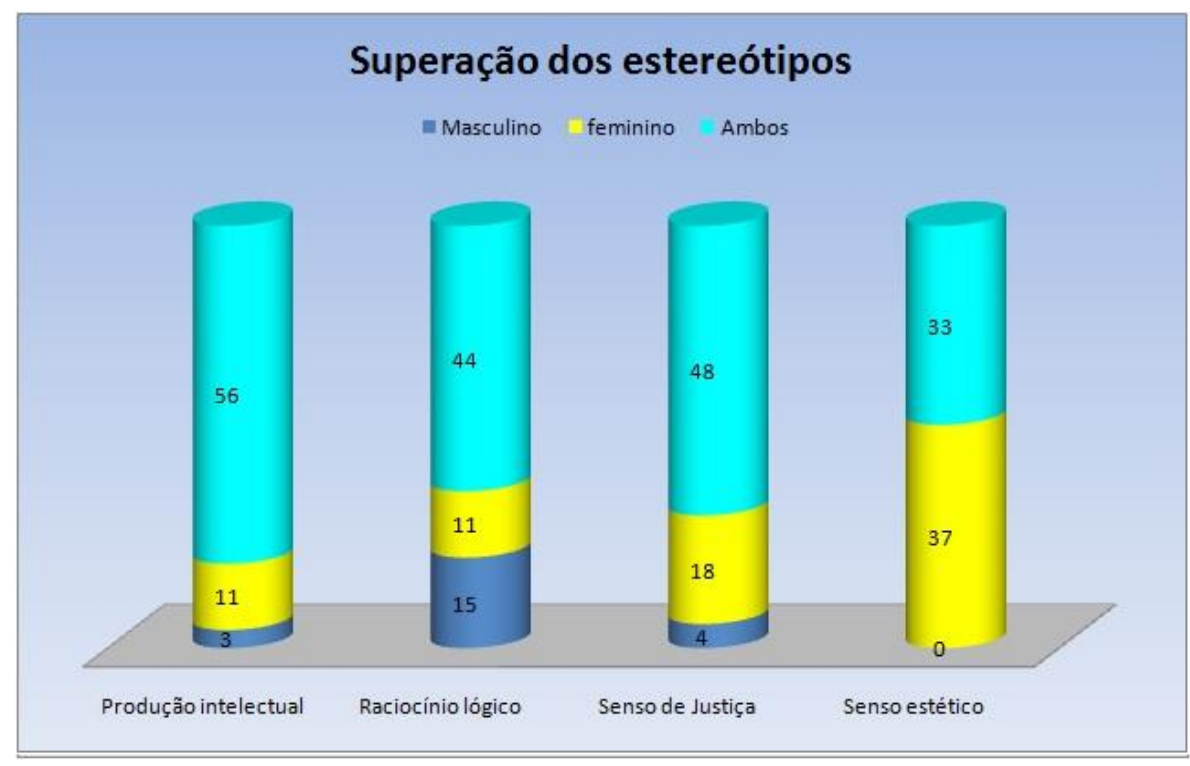

Figura 17 - Representação dos resultados referentes à Superação dos Estereótipos pelas participantes do Projeto Mulher do Milênio.

$\mathrm{Na}$ consulta às participantes, foi solicitada a classificação de atributos humanos como pertencentes ao gênero masculino, feminino ou a ambos. Verificou-se que a maioria classificou os estereótipos como sendo pertencentes tanto ao gênero masculino, quanto ao feminino. Este é o reflexo de uma concepção fundamental que embasa o projeto, incorporada pelas mulheres 
dele participantes: a inteligência humana não está associada a gênero, idade, raça ou a qualquer outro tipo de atributo, o que é veementemente reforçado no decorrer de todas as atividades desenvolvidas pelo Projeto Mulher do Milênio.

Como já enfatizado anteriormente, ainda requerem-se mudanças consideráveis à igualdade de gênero e à autonomia feminina. Entretanto, além das medidas já em andamento através de leis e políticas governamentais, fazse necessária a mudança de mentalidade e comportamento do ser humano em geral e, sobretudo, de cada mulher. Esta mudança refere-se à consciência do idêntico potencial humano da mulher em relação ao homem e do enorme espectro de resultados que se pode abrir na medida em que a humanidade passa a promover a inteligência ao feminino.

O Projeto Mulher do Milênio prima pela formação da inteligência ao feminino como aporte à autonomia da mulher e à igualdade de gênero, responsabilizando especialmente a mulher pela edificação de sua original identidade e pelo desinvestimento dos estereótipos dominantes de um determinado padrão de feminilidade, amplamente acreditado ainda na atualidade. Isso porque, em diversas circunstâncias, é ela própria quem se coloca em situação de inferioridade e, quando trazemos à baila o estereótipo da idade ou da beleza femininas, esta situação torna-se atroz. Porém, conforme demonstrado, no decorrer de duas décadas, dedicadas exclusivamente ao público feminino, o Projeto Mulher do Milênio conseguiu superar esta concepção mental estandardizada.

\subsection{6 - Liderança e empoderamento da mulher}

Conforme já mencionado, também em 2010, realizou-se o levantamento do número de mulheres em cargos de liderança nas empresas localizadas no Recanto Maestro, atualmente distrito de São João do Polêsine, no estado do Rio Grande do Sul.

O empoderamento da mulher - como expressão de controle do seu próprio ambiente e contribuição para o desenvolvimento social foi também avaliado através da empregabilidade e da promoção a posições de comando. Nos 14 empreendimentos ambientados no Distrito Recanto Maestro, 86\% das mulheres ocupavam cargos de poder em 2010, sendo que as mulheres formadas pelo Projeto Mulher do Milênio ocupam os principais cargos de poder e atuam direta ou indiretamente em diversos setores da economia e política locais.

Nestas mesmas empresas, foi também apurado outro indicador do Projeto Mulher do Milênio: número de mulheres em relação aos homens que compunham o quadro de colaboradores dos empreendimentos.

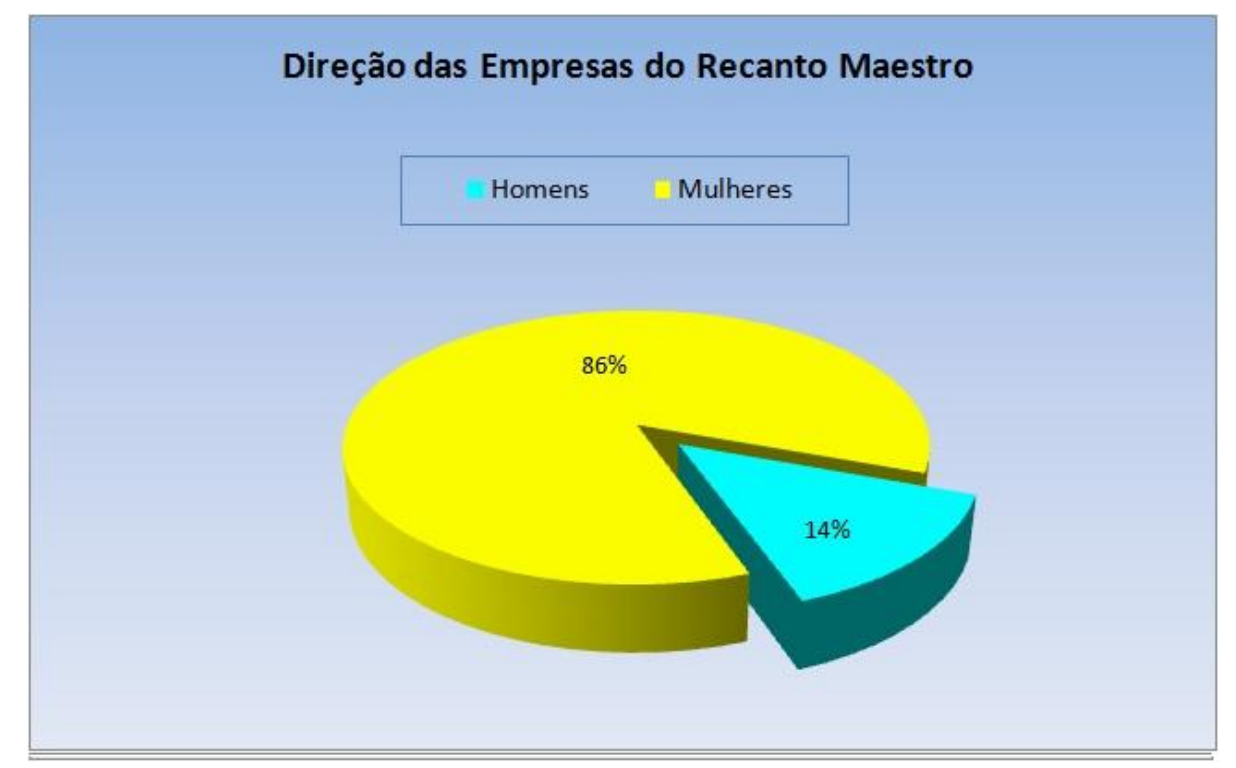

Figura 18 - Representação dos resultados referentes à Direção dos Empreendimentos no distrito Recanto Maestro após a implantação do Projeto Mulher do Milênio. 


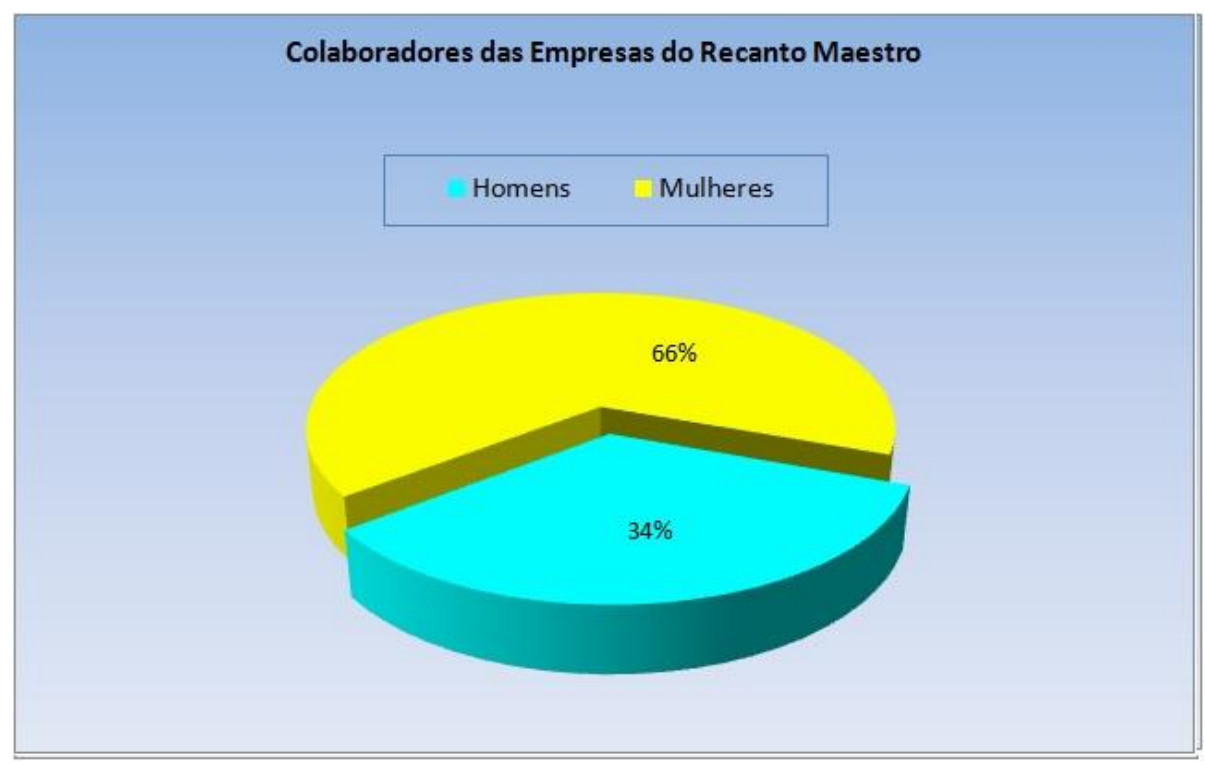

Figura 19 - Representação dos resultados referentes à quantidade de colaboradores dos empreendimentos no distrito Recanto Maestro após a implantação do Projeto Mulher do Milênio.

Os dados levantados demonstraram que $66 \%$ dos colaboradores das empresas, naquele período, eram mulheres, o que reforça este projeto social como um aliado na capacitação da mulher a fim de que ela adote uma atitude ativa no mercado de trabalho, mas que, sobretudo, esteja habilitada a ocupar posições de comando, conforme demonstrado na figura precedente.

O empoderamento da mulher é fundamental na corrida para o alcance da igualdade de gênero e valorização da mulher até o ano de 2015, pois favorece o equilíbrio tão almejado pela ONU numa globalização que ainda exclui a inteligência ao feminino, o que, indiscutivelmente, gera descompassos no avanço sustentável das economias locais e internacional.

\subsection{7- Impacto Social}

Outro indicador estabelecido pelo Projeto Mulher do Milênio alude ao número de mulheres que contribuem, direta ou indiretamente, através de ações sociais e da participação em ONGs para o alcance dos oito Objetivos de Desenvolvimento do Milênio.

Foi apurado um número crescente de mulheres que participavam de ONGs e averigou-se que $45 \%$ daquelas que participavam do Projeto Mulher do Milênio faziam parte de algum tipo de associação voltada ao desenvolvimento da mulher: classes profissionais, associações com escopo de desenvolvimento social, cultural e/ou intelectual.

Quanto à contribuição para o alcance dos oito Objetivos de Desenvolvimento do Milênio, verificamos que há cooperação, por parte das mulheres que acedem ao Projeto Mulher do Milênio, com todos os objetivos, sendo os de maior expressão aqueles que aludem à sustentabilidade ambiental ( $7^{\circ}$ objetivo), à educação ( $2^{\circ}$ objetivo $)$ e à promoção de autonomia da mulher e a igualdade ente os $\operatorname{sexos}\left(3^{\circ}\right.$ objetivo).

A investigação realizada junto às mulheres que integram o Projeto Mulher do Milênio demonstrou a eficácia e a efetividade de suas ações formativas e que culminaram com os resultados alcançados referentes à responsabilização pela conquista de sua autonomia: promoção da autoestima feminina, escolhas pessoais mais conscientes, ascensão no mercado de trabalho e a cargos de poder, liderança, prevenção e promoção de saúde, atuação enquanto agentes sociais, multiplicadoras dos conhecimentos adquiridos, das habilidades desenvolvidas e das novas atitudes adotadas para o seu protagonismo responsável ao desenvolvimento social, político, cultural e econômico - local e nacional. 


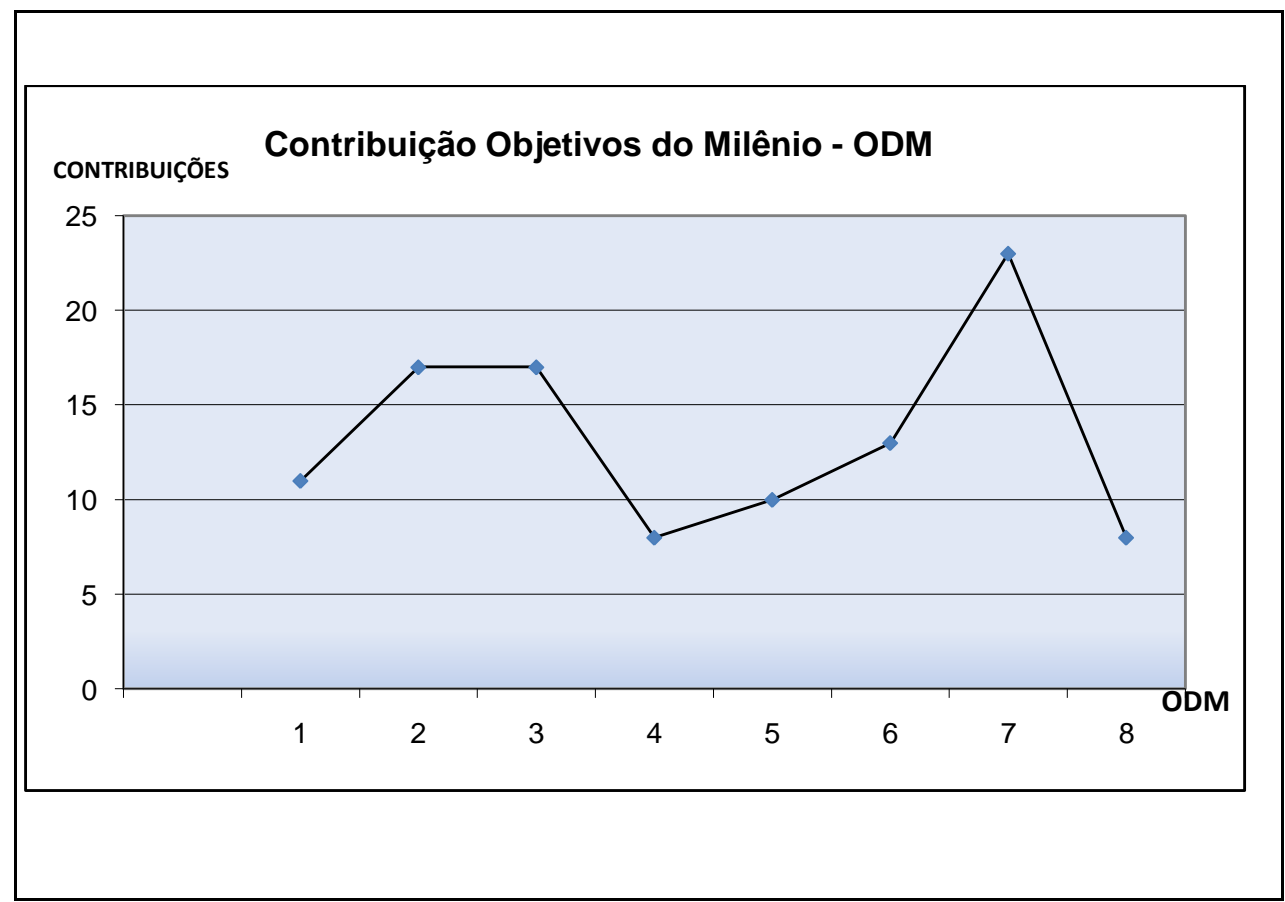

Figura 20 - Representação dos resultados referentes à colaboração do Projeto Mulher do Milênio para os Objetivos do Milênio. Fonte: Pesquisa Projeto Mulher do Milênio. Legenda: $1^{\circ}$ Erradicar a extrema pobreza e a fome; $2^{\circ}$ Atingir o ensino básico universal; $3^{\circ}$ Promover a igualdade de gênero e a autonomia das mulheres; $4^{\circ}$ Reduzir a mortalidade infantil; $5^{\circ}$ Melhorar a saúde materna; $6^{\circ}$ Combater o HIV/AIDS, a malária e outras doenças; $7^{\circ}$ Garantir a sustentabilidade ambiental; $8^{\circ}$ Estabelecer uma parceria mundial para o desenvolvimento.

Além disso, ficou evidenciado que, quando a mulher conquista sua autonomia, superando preconceitos e estereótipos, especialmente os relativos ao gênero, passa a ser uma contribuinte de valor no meio em que atua. Através do Projeto Mulher do Milênio, pode-se constatar que a responsabilização é um dos caminhos a ser seguido. A partir da obtenção da maturidade, psicológica e moral, e da conquista da própria autonomia, a mulher pode, finalmente, considerar-se cidadã e contribuinte de valor no plano familiar, sanitário, econômico e social.

\section{5 - Conclusão}

O Projeto Mulher do Milênio teve uma ação de vanguarda, seja pelo período em que iniciou suas atividades, seja pela sua abordagem humanista, baseada na metodologia ontopsicológica.

O Congresso Internacional "A mulher do Terceiro Milênio" aportou uma nova perspectiva ao incremento da inteligência ao feminino e, sobretudo, a este projeto. A sua principal contribuição foi a ênfase de Antonio Meneghetti ao mencionar que:

se não colocarmos o paralelo da inteligência feminina neste planeta, não teremos uma história. Se conseguirmos este paralelo, as ciências avançarão e tudo o mais progredirá.... Cada dia é a primeira manhã do mundo, depende de quem o honra, de quem o comanda, de quem objetiva a política do humanismo do seu tempo. Por isso, a presença de inteligências femininas é insubstituível para existir a possibilidade da posteridade (Meneghetti, 2000, p. 82).

Perante esta prerrogativa, o Projeto Mulher do Milênio passou a ter uma responsabilidade sem precedentes. Seu aporte à igualdade de gênero e à autonomia da mulher certamente foi, e prosseguirá sendo, aberto a todas as mulheres que tiveram verdadeiro interesse $\mathrm{e}$ real empenho em construir a equanimidade social, em resgatar os princípios do humanismo perene e em desenvolver a autonomia e a liderança feminina nos mais variados campos. Sem dúvida, a autonomia e a igualdade tornaram-se 
condição de sobrevivência para os indivíduos na sociedade contemporânea.

Conforme Soares $\left(1998^{7}\right)$, somente um indivíduo autônomo terá sucesso nas esferas econômica, psicológica, sócio-cultural e/ou política, pois é um indivíduo que interroga, reflete e delibera com liberdade e responsabilidade. Ou como diz Castoriadis, 'é capaz de uma atividade refletida própria', e não de uma atividade pensada por outro sem a sua participação.

Mesmo que no sistema social contemporâneo ainda seja difícil identificar, na mulher, a iniciativa para ser líder, empreendedora, dirigente, o Projeto Mulher do Milênio demonstrou que esta possibilidade pode se tornar concreta, viável, ainda que sejam necessários alguns anos para que a proporção de mulheres líderes - conscientes e responsáveis pelo próprio destino e de outrem seja harmônica a de homens em nossa sociedade. Contudo, através deste projeto, demonstra-se como podem ser multiplicadas ações que garantam o alcance deste intento, já que ele pode ser aplicado e replicado em outras circunstâncias socioculturais e econômicas, por meio de profissionais treinados e preparados tecnicamente para tal, levando-se em consideração que:

1. O método e o conteúdo utilizados garantem o alcance dos resultados previstos a partir de mulheres que efetivamente tenham decidido pela conquista de sua autonomia e liderança,

2. O Projeto já é aplicado em outras localidades (Rússia e Itália, por exemplo), assim como ocorre no distrito Recanto Maestro, onde mulheres locais e operadoras sociais se utilizam da metodologia ontopsicológica e investem seus esforços na construção e evolução da inteligência ao feminino;

3. Com diferentes parcerias que vão de instituições públicas a privadas, e através da ação de multiplicadoras, cuja faixa etária vai desde a juventude até a terceira idade, e que se propõem a trabalhar voluntariamente no Projeto, este pode ser replicado tendo a garantia de obtenção dos efeitos previamente presumidos.

\footnotetext{
${ }^{7}$ Texto publicado inicialmente no jornal "A Razão" em 25.06.98, disponível em: http://www.angelfire.com/sk/holgonsi/index.autono mia3.html acesso em: 30/07/12
}

O Projeto Mulher do Milênio - aliando as diversas abordagens sobre a feminilidade (psicológicas, antropológicas, sociais, culturais) ao uso de uma modalidade de training sociopsicológico residence e enfatizando a visão da inteligência ao feminino baseada na escola ontopsicológica - demonstra que as mulheres podem conhecer e construir a si mesmas como pessoas e líderes de ação, pois passam a nortear-se por uma consciência autêntica.

A partir do training sociopsicológico residence e de todas as atividades que são realizadas durante o período de sua ocorrência, as mulheres podem fazer a revisão de seus modelos existenciais e dar início a autenticação da própria consciência, já que este provê meios à verificação do estado de vida do sujeito e da funcionalidade de suas atitudes. De fato, a consciência autêntica é aquela que, antes de basear-se sobre modelos mentais e comportamentos adquiridos do externo, ou de prejuízos, constitui-se a partir da pura subjetividade, empregando a terminologia husserliana. A partir desta nova consciência, cada mulher pode acessar a especificidade intrínseca de valor de sua singular existência e construir uma história fundada sobre princípios de força e poder evidenciáveis.

\section{Referências}

Ferreira, A. B. H. (1986). Novo dicionário da língua portuguesa. Rio de Janeiro: Nova Fronteira.

Gil, A. C. (1988). Como Elaborar Projetos de Pesquisa. São Paulo, Editora Atlas S.A.

Gomes, A. S. M. (2009). Sub-representação feminina na política é constatada também nos Secretariados dos Estados e das Capitais. Revista do Observatório Brasil da Igualdade de Gênero, 1(1), 82-85.

Guimarães, S. É. R., \& Boruchovitch, E. (2004). O estilo motivacional do professor e a motivação intrínseca dos estudantes: uma perspectiva da Teoria da Autodeterminação. Psicologia: Reflexão e Crítica, 17(2),143150. Recuperado em 27 Novembro, de http://www.scielo.br/scielo.php?script=sci_a rttext\&pid=S0102$79722004000200002 \& \operatorname{lng}=$ pt\&nrm=iso\&tln $\mathrm{g}=\mathrm{pt}$ 
Meneghetti, A. (2000). A mulher do III milênio. Recanto Maestro: Ontopsicologica Ed.

Meneghetti, A. (2005a). Residence Ontopsicológico. Práxis e filosofia existencial. ( $3^{\mathrm{a}}$ Ed.). Recanto Maestro: Ontopsicologica Ed.

Meneghetti, A. (2007). La femminilità come sesso, potere, grazia (5. ed.). Roma: Psicologica Editrice.

Meneghetti, A. (2010). Manual de Ontopsicologia (4. ed.). Recanto Maestro: Ontopsicológica Editora Universitária.

Meneghetti, A. (2008). Dicionário de Ontopsicologia. Recanto Maestro: Psicologica Editrice.

Pérez Sedeño, E. (2001). La perspectiva del género en ciencia y tecnología: innovación y nuevacaracterización de las disciplinas. In J. A. L. CEREZO, \& J. M. S. RON, Ciencia, tecnología, sociedad y cultura en el cambio de siglo. Madrid: Biblioteca Nueva.

Presidência da República. (2008). II Plano Nacional de Políticas para as Mulheres. Recuperado em 20 de Janeiro, 2012, de http://bvsms.saude.gov.br/bvs/publicacoes/II _PNPM.pdf.
Soares, H. (1998). A importância da autonomia. Recuperado em 27 Novembro 2012, de http://www.angelfire.com/sk/holgonsi/index. autonomia3.html

TERCEIRO MILÊNIO: inteligência, poder e liderança feminina. Psicologia do líder. http://psicologiadolider.blogspot.com/2009/ 12/terceiro-milenio-inteligencia-podere.html.

UNITED NATIONS GLOBAL COMPACT. www.unglobalcompact.org/news/13-03-082010

WHO definition of Health. (1946). World Health Organization. Recuperado em, de http://www.who.int/about/definition/en/print .html

Recebido em 31 de Janeiro de 2012 Texto reformulado em 02 de Outubro de 2012 Aceite em 03 de Outubro de 2012 Publicado em 31 de Dezembro de 2012 